\title{
A finite element study on the fracture initiation at the zirconia/ veneer interface: An application in dental materials
}

\author{
M. M. Mirsayar ${ }^{\mathrm{a} *}$ and A. T. Samaei ${ }^{\mathrm{b}, \mathrm{c}}$
}

${ }^{a}$ Zachry Department of Civil Engineering, Texas A\&M University, College Station, TX 77843-3136, USA

${ }^{b}$ School of Engineering, University of California Merced, Merced, California 95343, USA

${ }^{c}$ Young Researchers \& Elite Club, Chalous Branch, Islamic Azad University, Chalous, Iran

\begin{tabular}{l}
\hline A R T I C L E I N F O \\
\hline Article history: \\
Received 6 April, 2015 \\
Accepted 20 July 2015 \\
Available online \\
23 July 2015 \\
\hline Keywords: \\
Interface crack \\
Zirconia \\
Veneer \\
Fracture initiation \\
Finite element \\
\end{tabular}

\section{A B S T R A C T}

Zirconia/ veneer bi-layered components are extensively used in dental restoration technology to improve resistance of tooth's surface from decay. The direction of the fracture propagation at the interface of zirconia and veneer is investigated in this paper. Finite element analysis is performed on a bi-material four point bend specimen in different geometries, and the fracture initiation angle is obtained using maximum tangential stress (MTS) criterion. The effect of specimen geometry on the fracture initiation angle is discussed. Because an interface crack may propagate through interface or kink into one of the materials, some comments are given to determine under which condition "interface de-bounding" will be happened.

\section{Introduction}

Restored teeth undergo complex loading conditions during their service life (Kotousov et al., 2011; Chai et al., 2014; Kosyfaki \& Swain 2014). Veneers which are made from dental porcelain or composite, are widely used in dentistry to protect tooth's surface from decay. In dental prostheses, the zirconia-based bi-material restorations are widely employed to reform the damaged parts of teeth. That is because the veneering porcelain sintered on zirconia (zirconia/ veneer interface) has a high strength (Fischer et al., 2008; Gostemeyer et al., 2010; Mosharraf et al., 2011; Kim et al., 2011).

In a restored tooth, under service condition, cracks may develop at the interface of zirconia and veneer as a result of the external mechanical loading. Thus, the study of fracture propagation condition at the interface of the zirconia and veneer is an important issue in the field of dentistry. Generally, the fracture in either homogeneous or bi-material media has widely been investigated by many researchers so far (Ayatollahi \& Aliha 2011; Aliha \& Ayatollahi 2008, 2012; Arabi et al., 2013; Ayatollahi et al.,

* Corresponding author. Tel.: +1 (979) 7776096

E-mail addresses: mirmilad@tamu.edu (M. M. Mirsayar) 
2010a,b, 2011a; Ayatollahi \& Mirsayar, 2011; Mirsayar, 2013, 2014a, b; Mirsayar \& Samaei, 2013, 2014; Mirsayar et al., 2014; Mirsayar \& Park 2015). Previously, the researchers have mostly focused on the enhancement of the bond strength rather than the fracture mechanics aspect of the zirconia/ veneer interfaces (Mosharraf et al., 2011; Kim et al., 2011). However, in the past few years, researchers were interested in interfacial fracture resistance of the all-ceramic restorations (Kotousov et al., 2011; Gostemeyer et al., 2012). Several fracture test specimens are employed by the researchers in the past to investigate the interfacial fracture resistance of the specimens containing a bi-material and simple cracks (Ayatollahi et al., 2013; Charalambides et al., 1989; Yuuki \& Xu, 1992; Mirsayar 2014c, 2015). Among them, the bi-material four-point bend specimen developed by Charalambides et al. (1989) has widely been accepted by the researchers. They have conducted experiments on the bi-material fourpoint bend specimens made from Aluminum and PMMA.

There are several fracture criteria to investigate the fracture initiation conditions at the interfacial crack tip. The well-known fracture criteria are: the maximum tangential stress (MTS) (Yuuki \& Xu, 1992), $K_{I I}=0$ (Cotterel \& Rice, 1980), and energy release rate (G) (He \& Hutchinson, 1989). However, these criteria are modified recently to provide more accurate estimation of the test results depending on different specimen geometries and boundary conditions. For instance, Mirsayar (2014a) showed that to achieve an accurate estimation of the interfacial fracture resistance, the first non-singular stress term of the elastic stress field (called T-stress) should also be considered when employing the MTS criterion.

In this paper, the fracture initiation condition at the interface of the zirconia and veneer is studied using bi-material four-point bend specimen suggested by Charalambides et al. (1989). The finite element software ABAQUS is employed to simulate the specimen in different geometries. For each case, the direction of the fracture initiation is obtained using the MTS criterion. Finally, some comments are given about the possibility of the crack kinking out of the interface as well as crack propagation through the interface.

\section{Problem Statement}

Fig. 1 shows the general configuration of the bi-material four-point bend specimen made from zirconia and veneer. The specimen has a central notch through the thickness of the veneer (top layer) which meets the middle of the symmetrical interface crack. The specimen is simulated in different thickness layer ratio $\left(h_{1} / h_{2}=0.5,1,2\right)$ and different normalized crack sizes $(a / c=0.1,0.3)$. The elastic properties of the veneer (IPS e.max Ceram) and zirconia (Lava Zirconia) are $E_{\mathrm{v}}=70 G P a, v_{\mathrm{v}}=0.27$ and $E_{\mathrm{z}}=210 G P a, v_{\mathrm{z}}=0.31$, respectively, where $E_{i}$ is the elastic modulus and $v_{i}$ is the Poisson's ratio of each material ( $i \equiv \mathrm{v}, \mathrm{z})$ (Wang et al., 2014).

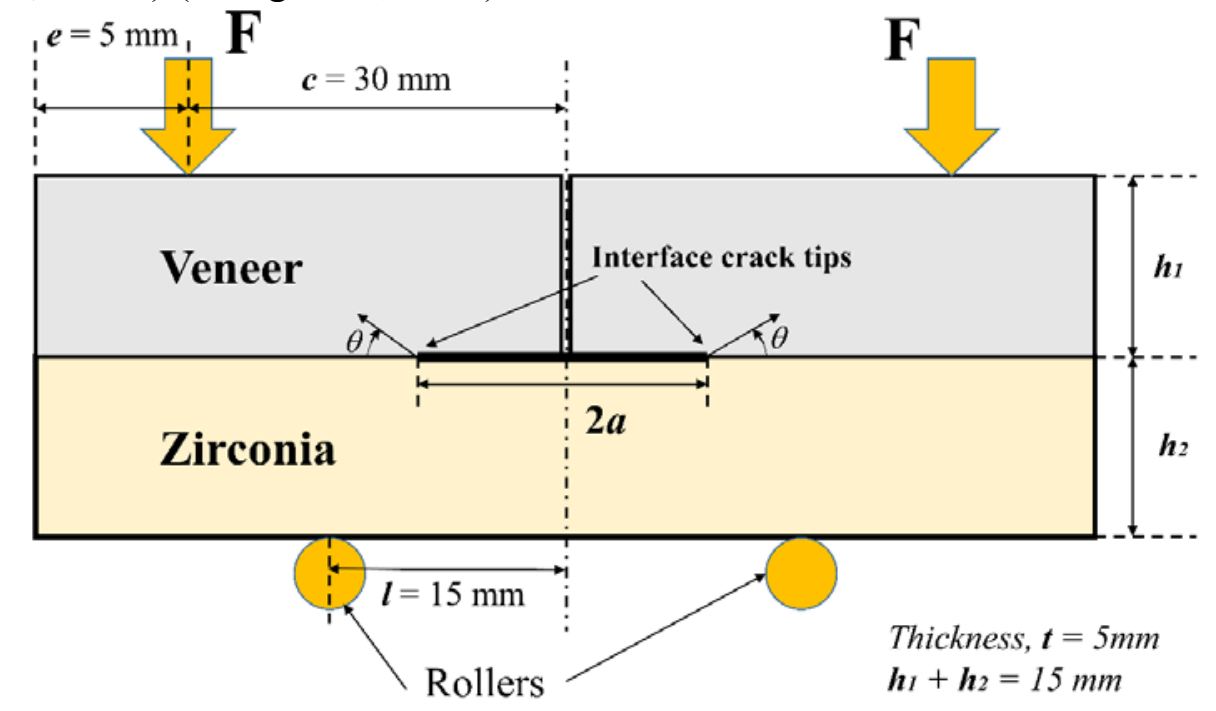

Fig. 1. General configuration of the bi-material four point bend specimen 
When the specimen is loaded, the interfacial crack may propagate through the interface or may kink into one of the materials depending on the strength of the interface. Based on the experimental observation given in the literature (see for instance, Wang et al., 2014) the zirconia / veneer bonded joints can be considered as "strong interfaces", and hence, the interface crack usually kinks into one of the materials instead of growing through the interface. However, the mechanism of the crack propagation at the interface is affected by the strength of the interface as well as each material.

\section{Results and Discussion}

\subsection{Finite element simulation of the specimen}

Fig. 2 shows a typical finite element mesh generated using eight node plane strain elements along with an expanded view of the crack tip singular elements (for $h_{1} / h_{2}=1$ and $a / c=0.1$ ). The specimen is simulated in different geometries to obtain the effect of geometry on the crack initiation condition at the interface crack tip.

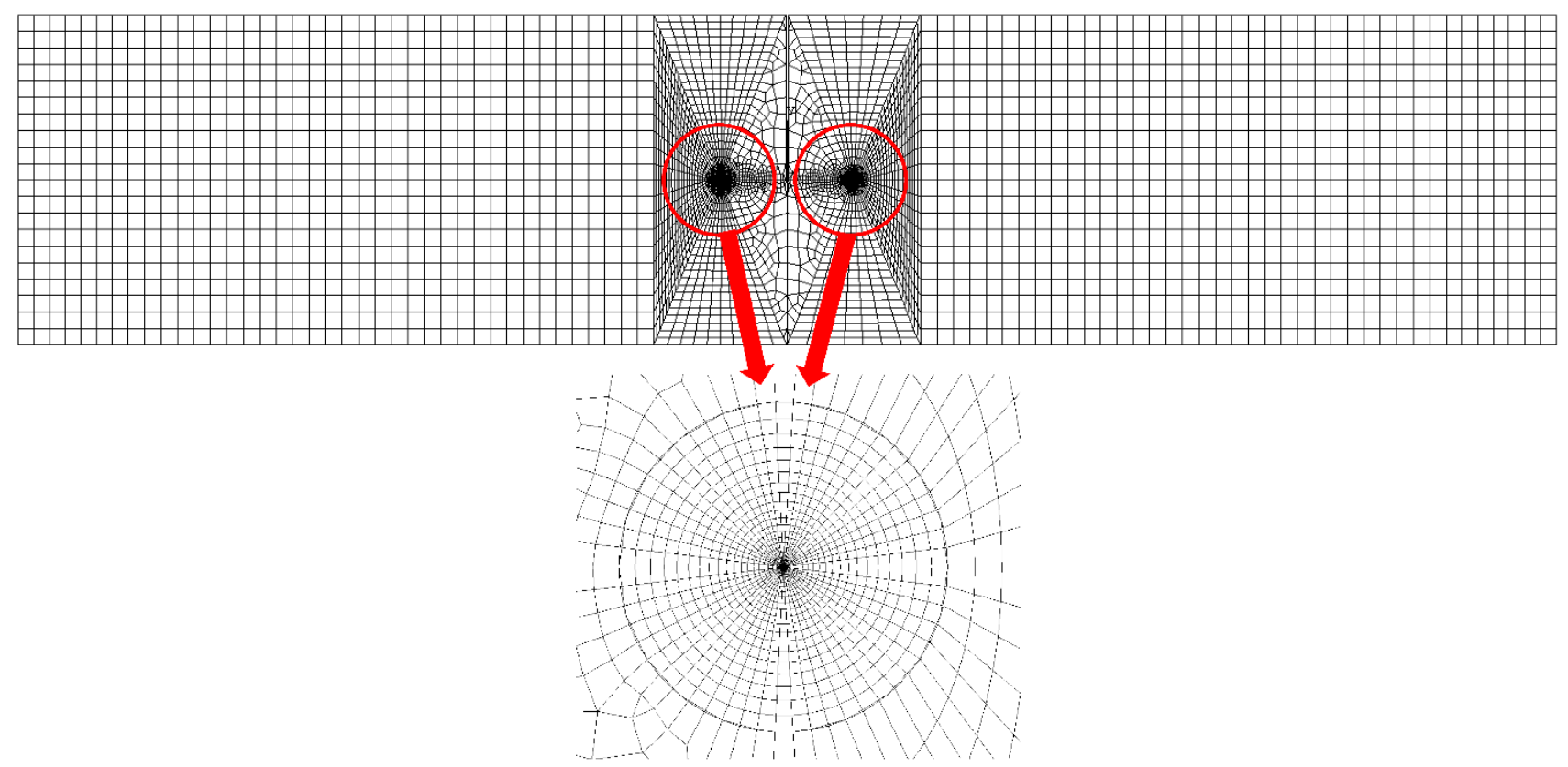

Fig. 2. Typical finite element mesh pattern of the bi-material four-point bend specimen

\subsection{MTS criterion for initiation at the crack tip}

Based on the MTS criterion, for brittle materials, the crack propagates at the critical distance of $r_{c}$ from the crack tip in direction where the tangential stress, $\sigma_{\theta \theta}$, reaches its ultimate strength. This criterion was developed originally for problem of a crack which exists in a homogeneous media (Erdogan \& Sih, 1963) and since then has been successfully used for predicting the mixed mode brittle fracture of various brittle and homogenous materials (such as Williams \& Ewing, 1972; Awaji \& Sato, 1978; Shetty et al., 1987, Maccagno \& Knott 1989; Suresh et al., 1990; He et al., 1990; Smith et al., 2001; Aliha \& Ayatollahi, 2008, 2011, 2014; Ayatollahi et al., 2006, 2008, 2011b; Aliha et al., 2008, 2012; Ayatollahi \& Aliha 2008; Saghafi et al., 2010). However, by the same concept, the MTS criterion could be applied for the interface cracks by controlling the ultimate strength of both materials (at their corresponding critical distances, $r_{c}^{(i)}$ ) as well as the strength of the interface. For "strong interfaces", the MTS criterion could be expressed as follows; 


$$
\left\{\begin{array}{l}
\left(\frac{\partial \sigma_{\theta \theta}^{(i)}}{\partial \theta}\right)_{r_{c}^{(i)}, \theta_{0}^{(i)}}=0 \\
\left(\frac{\partial^{2} \sigma_{\theta \theta}^{(i)}}{\partial \theta^{2}}\right)_{r_{c}^{(i)}, \theta_{0}^{(i)}}<0
\end{array},\right.
$$

where the critical distance, $r_{c}^{(m)}$, is defined as;

$$
r_{c}^{(i)}=\frac{1}{2 \pi}\left(\frac{K_{I C}^{(i)}}{\sigma_{C}^{(i)}}\right)^{2},
$$

where $K_{I C}^{(i)}$ and $\sigma_{C}^{(i)}$ are fracture toughness and ultimate tensile stress of each material, respectively. The elastic tangential stress field, $\sigma_{\theta \theta}$, is expressed in the form of a series of expansion with infinite terms containing singular (first and second terms) and nonsingular terms, as follows;

$$
\sigma_{\theta \theta}^{(i)}=\frac{K_{1}}{\sqrt{2 \pi r}} f_{\theta \theta, 1}^{(i)}+\frac{K_{2}}{\sqrt{2 \pi r}} f_{\theta \theta, 2}^{(i)}+T^{(i)}+(\text { H.O.T }),
$$

where, $K_{1}$ and $K_{2}$ are the stress intensity factors corresponding to opening and sliding mode, respectively. The parameter $T$, called T-stress, corresponds to the first non-singular stress term (more details about this term can be found in Mirsayar (2014a)). Although, in vicinity of the crack tip, the singular terms can reasonably predict the tangential stress field, it is recently shown by Mirsayar (2014a) that the first non-singular term sometimes plays an important role in prediction of the tangential stress distribution as well as the fracture initiation conditions around the crack tip. However, in this paper, the fracture initiation direction is predicted by the tangential stress which is directly obtained through the finite element analysis.

\subsection{Finite element results}

Fig. 3 shows the distribution of the normalized tangential stress in different angles, $\theta$, in two normalized crack lengths, $a / c=0.1$ and 0.3 . All curves are plotted at the radial distance of $r=0.2 \mathrm{~mm}$ which is within the regular range of the critical distances reported for ceramic materials (Aliha and Ayatollahi, 2012). It is seen that normalized tangential stress increases by increasing $h_{1} / h_{2}$ ratio. That means by increasing the thickness of the veneer (top layer) and decreasing the thickness of the zirconia, the tangential stress at the interfacial crack tip is increased and as a results, the fracture load is decreased.

According to Fig. 3, the tangential stress reaches its maximum value in zirconia part of the specimen. However, depending on the strength of the interface, crack may kink into the zirconia part or propagate through the interface. It should be noted that regardless of the stiffness of the veneer part, the crack will never kink into the zirconia part because the tangential stress at the veneer part reaches its maximum value at the interface. It also could be seen from Fig. 3 that the ratio of $\sigma_{z}$, max $/ \sigma_{\text {int }}$ is decreased by the increasing $h_{1} / h_{2}$ ratio $\left(\sigma_{z}\right.$, max and $\sigma_{i n t}$ are the maximum value of the normalized tangential stress in zirconia part and at the interface, respectively). That means by increasing the $h_{1} / h_{2}$ ratio, the possibility of crack propagation through the interface is decreased by increasing $h_{1} / h_{2}$ ratio. In other words, the simulation results show that, for $a / c=0.1$ and 0.3 , the interface strength (under pure tension) must be at least 2.5 times weaker than the tensile strength of the zirconia for having "interface 
de-bounding" (crack propagation through the interface). Also the comparison between results for $a / c=$ 0.1 and $a / c=0.3$ shows that the possibility of the interface de-bounding slightly decreases by increasing the crack length (assuming the same interface strength).

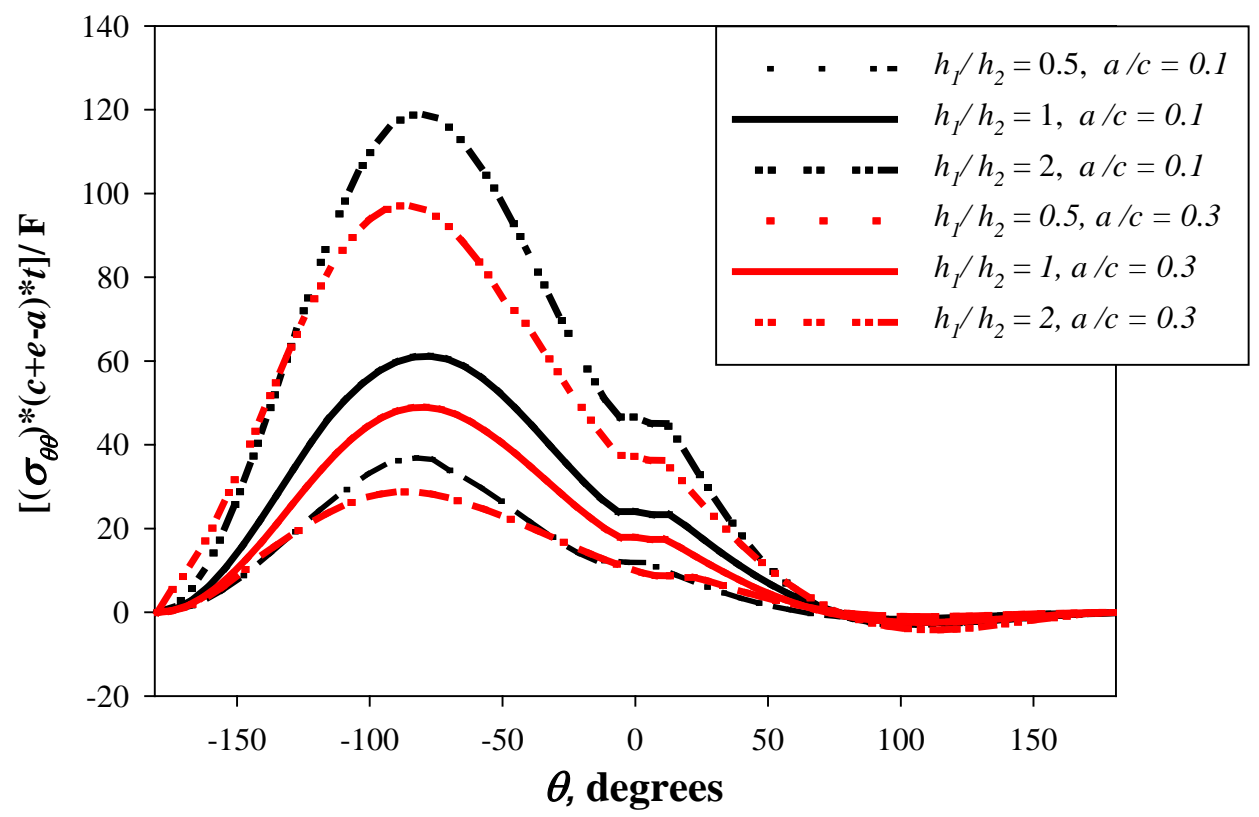

Fig. 3. Distribution of the normalized tangential stress versus tangential direction at $r=r_{c}=0.2 \mathrm{~mm}$

Assuming a strong interface in which the crack kinks into the zirconia part, the fracture initiation angle (with respect to the interface) in zirconia part slightly decreases by increasing $h_{1} / h_{2}$ ratio from $78^{\circ}$ to $-82^{\circ}$ and from $-80^{\circ}$ to $-86^{\circ}$ for $a / c=0.1$ and 0.3 , respectively. That means the fracture propagation angle in zirconia part slightly increases by increasing the crack length. It is also observed from Fig. 3 that distribution of the tangential stress field in veneer part approaches zero for $\theta>80^{\circ}$. That happens because of the central notch through the thickness of the veneer which provides a stress free area at the veneer part for small values of $a / c$ ratio. The variation of the normalized stress intensity factors versus the $h_{1} / h_{2}$ ratio and for both normalized crack lengths is illustrated in Fig. 4.

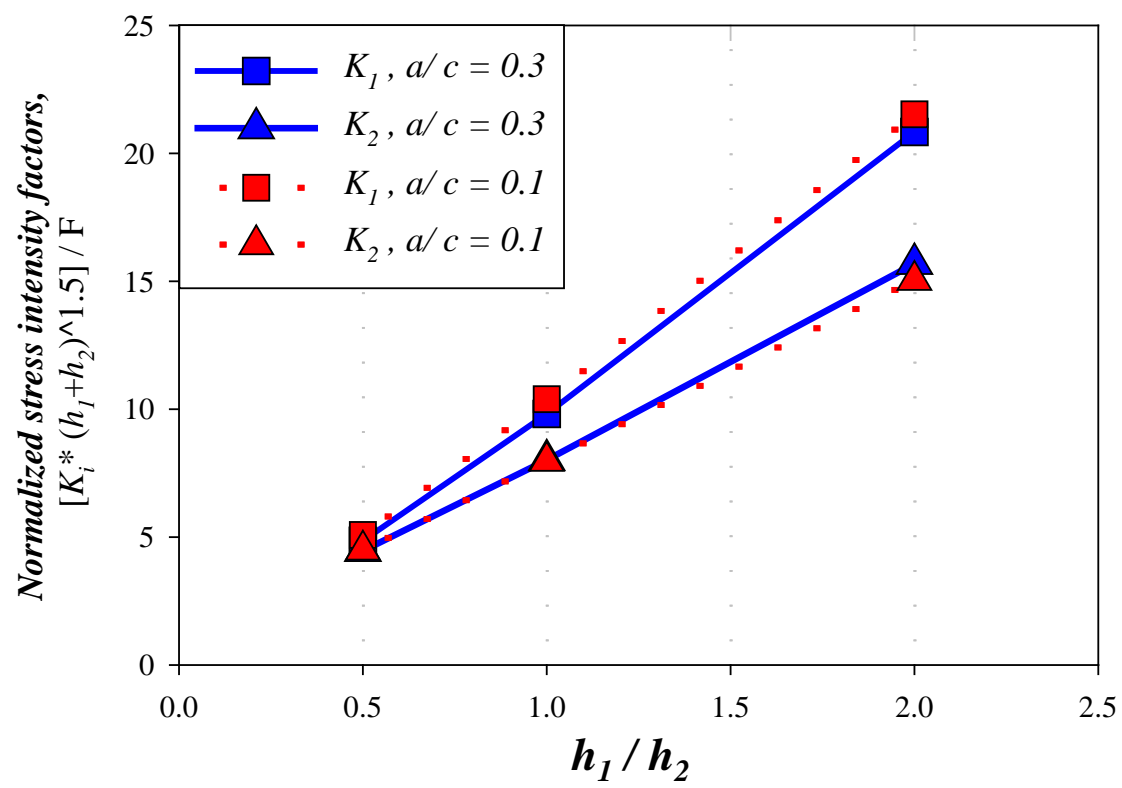

Fig. 4. Variation of the normalized stress intensity factors versus $h_{1} / h_{2}$ ratio 
It is shown that the both opening and sliding mode of the fracture are increased by increasing the $h_{1} / h_{2}$ ratio. However, the opening and sliding stress intensity factors slightly decrease and increase by increasing the normalized crack length, respectively. That means by increasing the normalized crack length, the role of shear stress in the crack initiation condition becomes more important and conversely, the role of normal stresses becomes less important.

\section{Conclusion}

The bi-material four-point bend specimen, made from zirconia and veneer, is simulated in this paper in different geometries by means of finite element method. The fracture initiation direction is obtained for each cases and the geometry effects are discussed. The condition in which a crack propagates through the interface or kinks into one of the materials is highlighted. Although, the bi-material fourpoint bend specimen is a well-known fracture test specimen, no recommendation is currently given in literature for using this specimen for zirconia/ veneer interface which are widely used in dental materials. Therefore, the results of this paper could be useful in standardization of the zirconia/ veneer fracture tests.

\section{References}

Aliha, M. R. M., \& Ayatollahi, M. R. (2008). On mixed-mode I/II crack growth in dental resin materials. Scripta Materialia, 59(2), 258-261.

Aliha, M. R. M., Ayatollahi, M. R., \& Pakzad, R. (2008). Brittle fracture analysis using a ring-shape specimen containing two angled cracks. International Journal of Fracture, 153(1), 63-68.

Aliha, M. R. M., \& Ayatollahi, M. R. (2011). Mixed mode I/II brittle fracture evaluation of marble using SCB specimen. Procedia Engineering, 10, 311-318.

Aliha, M. R. M., Sistaninia, M., Smith, D. J., Pavier, M. J., \& Ayatollahi, M. R. (2012). Geometry effects and statistical analysis of mode I fracture in guiting limestone. International Journal of Rock Mechanics and Mining Sciences, 51, 128-135.

Aliha, M.R.M. \& Ayatollahi, M.R. (2012). Analysis of fracture initiation angle in some cracked ceramics using the generalized maximum tangential stress criterion. International Journal of Solids and Structures, 49, $1877-1883$.

Aliha, M. R. M., \& Ayatollahi, M. R. (2014). Rock fracture toughness study using cracked chevron notched Brazilian disc specimen under pure modes I and II loading-A statistical approach. Theoretical and Applied Fracture Mechanics, 69, 17-25.

Arabi, H., Mirsayar, M.M., Samaei A.T., \& Darandeh, M. (2013). Study of characteristic equation of the elastic stress field near bimaterial notches. Strength of Materials, 45 (5), 598-606.

Awaji, H., \& Sato, S. (1978). Combined mode fracture toughness measurement by the disk test. Journal of Engineering Materials and Technology, 100(2), 175-182.

Ayatollahi, M. R., Aliha, M. R. M., \& Hassani, M. M. (2006). Mixed mode brittle fracture in PMMAan experimental study using SCB specimens. Materials Science and Engineering: A, 417(1), 348356.

Ayatollahi, M. R., \& Aliha, M. R. M. (2008). Mixed mode fracture analysis of polycrystalline graphitea modified MTS criterion. Carbon, 46(10), 1302-1308.

Ayatollahi, M.R., Mirsayar, M.M., \& Nejati, M. (2010a). Evaluation of first non-singular stress term in bi-material notches. Computational Materials Science, 50, 752-60.

Ayatollahi, M.R., Nejati M. \& Mirsayar, M.M. (2010b). An overdeterministic method for stress analysis of bi material corners and interface cracks using finite element method. Proceedings of the $9^{\text {th }}$ Conference of Iranian Aerospace Society, Tehran, Iran.

Ayatollahi, M.R. \& Mirsayar, M.M. (2011). Kinking angles for interface cracks. Procedia Engineering, $10,325-329$.

Ayatollahi, M. R., \& Aliha, M. R. M. (2011). Fracture analysis of some ceramics under mixed mode loading. Journal of the American Ceramic Society, 94(2), 561-569. 
Ayatollahi, M.R., Mirsayar, M.M., \& Dehghany, M. (2011a). Experimental determination of stress field parameters in bi-material notches using photoelasticity. Materials and Design, 32, 4901-4908.

Ayatollahi, M. R., Aliha, M. R. M., \& Saghafi, H. (2011b). An improved semi-circular bend specimen for investigating mixed mode brittle fracture. Engineering Fracture Mechanics, 78(1), 110-123.

Ayatollahi, M.R., Dehghany, M., \& Mirsayar, M.M. (2013). A comprehensive photoelastic study for mode I sharp V-notches. European Journal of Mechanics A/ Solids, 37, 216-230.

Chai, H., Lee, J.J.W., Mieleszko, A.J., Chu, S. J., \& Zhang, Y. (2014). On the interfacial fracture of porcelain/ zirconia and graded zirconia. Acta Biomaterialia, 10, 3756 - 3761.

Charalambides, P.G., Lund, J., Evans, A.G., \& McMeeking, R.M. (1989). A test specimen for determining the fracture resistance of bimaterial interfaces. Journal of Applied Mechanics, 56, 77 82.

Cotterell, B. \& Rice, J.R. (1980). Slightly curved or kinked cracks. International Journal of Fracture, 16 (2), 155-169.

Erdogan, F., \& Sih, G. C. (1963). On the crack extension in plates under plane loading and transverse shear. Journal of Fluids Engineering, 85(4), 519-525.

Fischer, J., Grohmann, P. \& Stawarczyk, B. (2008). Effect of Zirconia Surface Treatments on the Shear Strength of Zirconia/Veneering Ceramic Composites. Dental Materials Journal. 27, 448 - 454.

Gostemeyer, G., Jendras, M., Borchers, L., Bach, F.W., Stiesch, M. \& Kohorst, P. (2012). Effect of thermal expansion mismatch on the Y-TZP/veneer interfacial adhesion determined by strain energy release rate. Journal of Prosthodontic Research, 56, 93-101.

Gostemeyer, G., Jendras, M., Dittmer, M.P., Bach, F.W., Stiesch, M. \& Kohorst, P. (2010). Influence of cooling rate on zirconia/veneer interfacial adhesion. Acta Biomaterialia, 6, 4532-4538.

He, M.Y. \& Hutchinson, J.W. (1989). Kinking of a crack out of an interface. Journal of Applied Mechanics, 111, 270-278.

He, M. Y., Cao, H. C., \& Evans, A. G. (1990). Mixed-mode fracture: the four-point shear specimen. Acta Metallurgica et Materialia, 38(5), 839-846.

Kim, H.J., Lim, H.P., Park, Y.J. \&Vang, M.S. (2011). Effect of zirconia surface treatments on the shear bond strength of veneering ceramic. The Journal of Prosthetic Dentistry. 105, 315-322.

Kosyfaki, P. \& Swain, M.V. (2014). Adhesion determination of dental porcelain to zirconia using the Schwickerath test: Strength vs. fracture energy approach. Acta Biomaterialia, 10, 4861-4869.

Kotousov, A., Kahler, B. \& Swain, M. (2011). Analysis of interfacial fracture in dental restorations. Dental Materials, 27(11), 1094-1101.

Maccagno, T. M., \& Knott, J. F. (1989). The fracture behaviour of PMMA in mixed modes I and II. Engineering Fracture Mechanics, 34(1), 65-86.

Mirsayar, M.M. (2013). Calculation of stress intensity factors for an interfacial notch of a bi-material joint using photoelasticity. Engineering Solid Mechanics, 1, 149-153.

Mirsayar, M.M. (2014a). On fracture of kinked interface cracks-the role of T-stress. Materials and Design, 61, 117-123.

Mirsayar, M.M. (2014b). A modified maximum tangential stress criterion for determination of the fracture toughness in bi-material notches-Part 1: Theory. Engineering Solid Mechanics, 2 (4), $277-$ 282.

Mirsayar, M.M. (2014c). A new mixed mode fracture test specimen covering positive and negative values of T-stress. Engineering Solid Mechanics, 2, 67-72.

Mirsayar, M.M. (2015). Three Dimensional Investigation of Mode I Stress Intensity Factor Variations in Crack Front Using Finite Element Method. American Journal of Engineering and Applied Sciences, 8 (1), 11-16.

Mirsayar, M.M., Aliha, M.R.M. \& Samaei, A.T. (2014). On fracture initiation angle near bi-material notches-effects of first non-singular stress term. Engineering Fracture Mechanics, 119, 124-131.

Mirsayar, M.M., \& Park, P. (2015). The role of T-stress on kinking angle of interface cracks. Materials and Design, 80, 12-19. 
Mirsayar, M.M. \& Samaei, A.T. (2013). Photoelastic study of bi-material notches: Effect of mismatch parameters. Engineering Solid Mechanics, 1 (1), 21-26.

Mirsayar M. M. \& Samaei, A. T. (2014). Application of maximum tangential stress criterion in determination of fracture initiation angles of silicon/glass anodic bonds. Engineering Solid Mechanics, 2 (3), 145-150.

Mosharraf, R., Rismanchian, M., Savabi, O., \& Ashtiani, A.H. (2011). Influence of surface modification techniques on shear bond strength between different zirconia cores and veneering ceramics. The Journal of Advanced Prosthodontics, 3, 221-228.

Saghafi, H., Ayatollahi, M. R., \& Sistaninia, M. (2010). A modified MTS criterion (MMTS) for mixedmode fracture toughness assessment of brittle materials. Materials Science and Engineering: A, 527(21), 5624-5630.

Shetty, D. K., Rosenfield, A. R., \& Duckworth, W. H. (1987). Mixed-mode fracture in biaxial stress state: application of the diametral-compression (Brazilian disk) test. Engineering Fracture Mechanics, 26(6), 825-840.

Smith, D. J., Ayatollahi, M. R., \& Pavier, M. J. (2001). The role of T-stress in brittle fracture for linear elastic materials under mixed-mode loading. Fatigue \& Fracture of Engineering Materials \& Structures, 24(2), 137-150.

Suresh, S., Shih, C. F., Morrone, A., \& O'Dowd, N. P. (1990). Mixed-Mode Fracture Toughness of Ceramic Materials. Journal of the American Ceramic Society, 73(5), 1257-1267.

Wang, G., Zhang, S., Bian, C., \& Kong, H. (2014). Fracture mechanics analyses of ceramic/veneer interface under mixed-mode loading. Journal of the Mechanical Behavior of Biomedical Materials, 39, 119-128.

Williams, J. G., \& Ewing, P. D. (1972). Fracture under complex stress-the angled crack problem. International Journal of Fracture Mechanics, 8(4), 441-446.

Yuuki, R. \& Xu, J.Q. (1992). Stress based criterion for an interface crack kinking out of the interface in dissimilar materials. Engineering Fracture Mechanics. 41(5), 635-644. 